\title{
CAPITAL SOCIAL NA CONFIGURAÇÃO DE ORGANIZAÇÃO INTERNACIONAL EM REDE: estudo de caso da AUGM
}

\section{1- Larissa Cristina Dal Piva Moreira*}

Mestre em Administração pela Universidade Federal do Paraná (UFPR), Brasil. laridalpiva@gmail.com

http://lattes.cnpq.br/7951863941276941

\section{2- Sandro Aparecido Gonçalves}

Doutor em Administração pela Fundação Getúlio Vargas (EAESP/FGV), Brasil.

Professor do Programa de Pós-Graduação em Administração da Universidade Federal do Paraná (UFPR), Brasil. sag2@uol.com.br

http://lattes.cnpq.br/4984241119348770

\section{3- Edson Ronaldo Guarido Filho}

Doutor em Administração pela Universidade Federal do Paraná (UFPR), Brasil.

Pesquisador do Instituto Brasileiro de Estudos e Pesquisas Sociais (Ibepes) e Professor do Programa de Mestrado e Doutorado em Administração da Universidade Positivo (UP), Brasil.

edson.guarido@ibepes.org.br

http://lattes.cnpq.br/2435628775717990

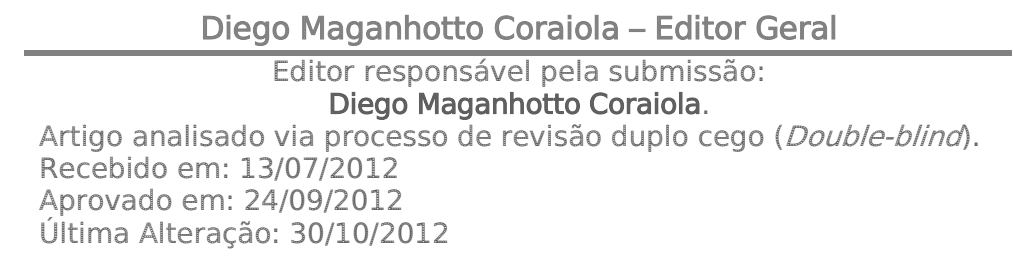

\footnotetext{
* Contato Principal: Universidade Federal do Paraná. Avenida Prefeito Lothário Meissner, 632, 20 andar Jd. Botânico.

Curitiba, PR - Brasil. CEP: 80210-170.
} 
CAPITAL SOCIAL NA CONFIGURAÇÃO DE ORGANIZAÇÃO INTERNACIONAL EM REDE: ESTUDO DE CASO DA AUGM

\section{RESUMO}

O presente trabalho emprega o conceito de capital social e como esse contribui na formação e evolução de uma rede internacional de universidades, por meio da análise de suas quatro dimensões em três momentos no tempo. O objeto escolhido para estudo de caso com abordagem qualitativa foi a Associação de Universidades Grupo Montevidéu (AUGM). Após análise dos dados, percebeu-se que, as relações interpessoais responsáveis pela sustentação da rede inter-universitária, gradativamente se institucionalizaram, permitindo-se falar em capital social organizacional.

\section{Palavras-chave}

Capital social, organização em rede, internacionalização de universidades.

\section{SOCIAL CAPITAL IN THE CONFIGURATION OF AN INTERNATIONAL NETWORK ORGANIZATION: THE CASE STUDY} OF AUGM

\section{ABSTRACT}

This study brings the concept of social capital and how this contributes to the formation and evolution of an international network of universities, through the analysis of its four dimensions into three different moments in time. The object chosen for the case study with a qualitative approach was the Association of Universities Grupo Montevideo (AUGM). After analyzing the data, it was found that interpersonal relationships responsible for supporting inter-university network, gradually became institutionalized, allowing it to identify an social organizational capital.

\section{Keywords}

Social capital, network organization, university internationalization. 


\section{Introdução}

As condições tecnológicas e de processamento de informações que se apresentam no final do século XX e agora, fazem com que as universidades enfrentem o desafio de internacionalizar-se e de participar de redes internacionais de cooperação entre instituições de ensino superior (Didriksson, 2006). Em concordância, Sebastián (2004) define a cooperação acadêmica internacional, como um conjunto de atividades realizadas entre instituições universitárias que, por meio de múltiplas modalidades, implica em uma associação e colaboração em temas de política e gestão interorganizacional.

Assumindo o capital social como "o conjunto de recursos, atuais ou potenciais, que estão ligados à posse de uma rede de relações mais ou menos institucionalizada, de conhecimento mútuo e reconhecimento" (Bourdieu, 1986, p.51), este artigo sustenta também como posições centrais, o entendimento de Granovetter (1992), Nahapiet e Goshal (1998), para analisar a relação desse conceito com a formação de uma organização em rede, inspirada pela pergunta de pesquisa: Como o capital social contribuiu na origem, evolução e consolidação da Associação de Universidades do Grupo de Montevidéu (AUGM)?

Para Lin (2001) e Nahapiet e Goshal (1998), o capital social em suas distintas dimensões, influencia na forma de interação nas redes porque facilita o fluxo de informação, exercendo influência nos agentes, além de apresentar credenciais sociais e reforçar a identidade e o reconhecimento dos atores da rede. Em adição, "diz respeito a características da organização social como confiança, normas e sistemas que contribuam para aumentar a eficiência da sociedade, facilitando as ações coordenadas" (Putnam, 2000, p. 177).

Dois objetivos são pretendidos. O primeiro, prático, é entender uma breve história da AUGM, a partir da distinção de capital social como uma propriedade de relações individuais, (capital social interpessoal) e seu nível institucionalizado que já permite acesso por indivíduos que previamente não possuam as mesmas relações interpessoais, mas que no nível organizacional estão disponíveis (capital social organizacional). Portanto, a emergência do fenômeno organizacional será tratada como um processo de transposição do capital social do nível interpessoal para o organizacional.

O segundo objetivo é teórico, será apresentado no último item deste artigo, e versa sobre a contribuição do capital social e a transposição de níveis como úteis para ampliar o escopo de entendimento do que se chama teoria das organizações.

Segue-se uma breve fundamentação teórica, procedimentos metodológicos, apresentação e análise de dados, incluindo os detalhes do caso, e as considerações finais e debate.

\section{Capital Social e Organizações em REDE}

A primeira utilização conhecida do conceito de capital social foi feita por Lyda Hanifan, em 1916, para explicar a importância do envolvimento da comunidade para o sucesso escolar, caracterizando capital social como elementos intangíveis da vida cotidiana: boa vontade, amizade, solidariedade, interação social entre os indivíduos e as famílias que compõem uma unidade social.

A partir dos anos de 1980, Pierre Bourdieu, James Coleman e Robert Putnam retomam o termo e amplificam seu significado, comportando diferenças, mas indicando o uso do conceito para a compreensão e apreensão de fenômenos sociais, neste artigo, alguns tipos de organizações, como: redes organizacionais, isto é, ligações entre organizações já existentes; e organizações em rede, ou seja, aquelas cujo propósito é facilitar as ligações com outras (AUGM). No caso dos estudos organizacionais que têm em sua tradição o uso do conceito de burocracia, uso deste conceito permite o debate acerca da diferença do contrato pressuposto para organização, desigual na burocracia e de igualdade para algumas organizações explicáveis por capital social, para o qual a AUGM é bastante ilustrativa.

Bourdieu (1986) define capital social, como um conjunto de recursos em uma rede, e é possível distinguir os elementos constitutivos deste capital: as relações sociais que permitem ao indivíduo obter recursos da rede, e a qualidade e quantidade desses recursos.

Para Coleman (1988), o capital social é intangível, só existe na relação entre os atores sociais, ao contrário do capital econômico e do intelectual, que podem ser propriedades do indivíduo. Assim, este tipo de capital não é um atributo dos indivíduos, mas um aspecto dependente do contexto e da estrutura social, ou seja, inerente à estrutura das relações entre dois ou vários atores. O capital social não está nem nos 
próprios atores, nem nos instrumentos físicos de produção, o que faz com que sua aquisição só ocorra "por meio de mudanças nas relações entre as pessoas, o que facilita a ação" (Coleman, 1988, p.100).

Em concordância, Putnam (2000, p. 177) define que o capital social "diz respeito à características da organização social como confiança, normas e sistemas que contribuam para aumentar a eficiência da sociedade, facilitando as ações coordenadas".

De acordo com Portes (1998), Bourdieu (1986) trabalha o conceito de capital social de forma instrumental, pois considera que as pessoas constroem suas relações tendo em vista os benefícios que obteriam posteriormente. Divergindo da visão individual utilitária de Bourdieu (1986), Coleman (1988) e Putnam (2000) defendem o capital social como bem público da sociedade. Percebe-se assim que, de acordo com Coleman (1988), o capital social é uma forma de transpor a estrutura social da ação racional, passando do nível micro para macro organizacional. No entanto, Bourdieu trata de uma relação específica que é captada do ponto de vista do indivíduo, na qual além da conversibilidade entre os capitais ser possível, o indivíduo é influenciado, mas não determinado pelas condições materiais (capital econômico), ou de conhecimento (capital intelectual), na medida em que o capital social é possível de ser acessado e convertido.

Em relação aos níveis em redes organizacionais, autores como Granoveter (1992), Burt (1992) e Lin (2001) seguiram próximos do entendimento de Bourdieu (1986) e avaliam o capital social na rede com foco na utilidade para os membros.

Granoveter (1973) contribui ao destacar a força dos laços fracos. Relações próximas envolvem tempo e energia para serem mantidas, nessas, o ator não sabe o que o outro sabe, mas sabe que o outro sabe, e a relação mantida pela intimidade permite o compartilhamento do conhecimento. Equivale dizer que é provável ter muitos colegas e conhecidos, mas não muitos amigos, essa relação é um exemplo de laço forte, e sua manutenção requer maior atenção. De outro lado, novidades, ideias ou informações podem ser obtidas com colegas e conhecidos, que exemplificam laços fracos. Essas intensidades de laço cumprem funções diferentes, complementares e não excludentes.

Assim considerado, segundo Burt (1992) o capital social pode, por meio de redes, intermediar conexões entre atores, na direção de incluir outros (laços fracos) como fonte de crescimento do capital social.

Burt (1992) ressalta também a importância da confiança e da reciprocidade para a eficiência das redes. A confiança presente nas relações entre os atores contribui para a manutenção dos vínculos sociais e o controle de comportamentos oportunistas e indesejados coletivamente. Nesse sentido, a confiança passa a ser preditora da conduta dos atores, requerendo, para tanto, a existência de normas de reciprocidade e de respeito mútuo. Daí, na visão do autor, a reciprocidade seria a norma mais relevante em termos de capital social.

Estas e outras características do capital social foram classificadas, de acordo com Nahapiet e Goshal (1998), em três dimensões:

- Dimensão estrutural: refere-se ao padrão de conexão entre os atores, incluindo as conexões e configurações da rede que descrevem o padrão de ligações em termos de mensuração como densidade, conectividade, hierarquia e adequação organizacional;

- Dimensão relacional: refere-se aos ativos que são criados e alavancados por meio do relacionamento e incluem atributos como identificação, confiança, normas, sanções, obrigações e expectativas;

- Dimensão cognitiva: refere-se aos recursos que representam visões compartilhadas, interpretações e sistemas de significados, por exemplo, a linguagem, códigos e narrativas.

Ao comentar a relação entre as dimensões, Nahapiet e Ghoshal (1998) propõem que nem todas as dimensões do capital social são mutuamente reforçadas, porém a dimensão estrutural do capital social influencia o desenvolvimento da dimensão relacional e cognitiva.

Koka \& Prescott (2002) identificam ainda a dimensão informacional do capital social, com três categorias analíticas baseadas no volume, diversidade e riqueza das informações. Quanto mais vínculos em uma organização, maior será o volume e a troca de informações, proporcionando mais oportunidades de aprendizagem, de geração de novos conhecimentos e de construção de compromissos mútuos.

Atendo-se aos autores já citados e sua participação no entendimento de que o capital social - que se separa da ideia de rede, sendo que esta deve ser entendida mais como elemento estrutural e como equivalência concreta do conceito de capital social - se constitui de recursos potenciais ou em uso; não uniformemente distribuídos, logo, comportando a diferença de laços fortes e fracos; em pelo menos quatro 
dimensões (relacional, cognitiva, estrutural e informacional); e pode ser, ainda que sempre coletivo, distinto, como interpessoal e organizacional.

\section{Procedimentos Metodológicos}

Com o pressuposto de que a motivação para criação ou participação em uma organização em rede nem sempre é dado por razões econômicas, mas por laços de afetividade e confiança entre membros, este trabalho assume uma concepção interpretativista, construcionista e evolucionária, com metodologia qualitativa e método de estudo de caso com entrevistas focadas (Godoi, 2006) e análise de redes sociais (Wasserman \& Faust, 1994).

O objeto de estudo escolhido foi a Associação de Universidades do Grupo Montevidéu (AUGM) e justifica-se, além do fator acessibilidade, por ser ainda o único caso do tipo - uma organização internacional em forma de rede -, agora com 28 Universidades-membros de diferentes países da América do Sul: Argentina, Brasil, Bolívia, Chile, Paraguai e Uruguai.

Foi realizado o mapeamento da rede no período de 1991 (ano de sua fundação) a 2011. Este foi possível por meio de informações secundárias, documentos históricos (atas de reuniões), o livro de 15 anos da organização, sites da AUGM e das universidades membros, e entrevistas (com distintos formatos) com membros da rede ao longo deste período, envolvendo Reitores e Delegados Assessores, professores e alunos intercambistas, sendo todas feitas in loco em cada país envolvido, na seguinte forma:

- Reitores (6), o fundador, e 2 Reitores de mandato recente e atual, e 3 intermediários;

- Delegados Assessores (28) atuais que se reuniram na capital do Paraguai (2011) em um evento da AUGM (Jornada de Jovens Pesquisadores);

- Professores e alunos intercambistas (29, depoimentos rápidos) participantes do evento.

A partir das informações obtidas acerca das relações existentes entre as universidades membros, foi realizado o mapeamento da rede AUGM considerando três momentos: 1991, 2001 e 2011, sem justificativa histórica, apenas para facilitar a estática comparada.

A análise de redes sociais (ARS) permitiu visualizar a estrutura da rede AUGM como toda a rede, laços entre os atores, e posição (Monge \& Contractor, 2001). O tratamento dos dados segue o protocolo típico desta análise, mas não pretende sustentar seus argumentos em questões matemáticas. Sua utilidade é restrita como recurso visual e auxiliar na triangulação dos dados.

Ressalta-se ainda que os dados tratados via UCINET não foram coletados por meio de escala, mas pela interpretação dos documentos, que apresentam a ordem de entrada dos membros e seus papéis, cruzados com os relatos das entrevistas para contra-checagem. Esta opção, que considera o dado secundário como mais importante, teve o objetivo de reduzir o efeito da percepção dos sujeitos que enxergam a AUGM a partir de referências históricas distintas, assim como momentos diferentes nos quais tomam conhecimento dela, o que o uso de uma escala desconsideraria.

Avaliado o conteúdo das entrevistas e dos mapas da rede gerados pelo UCINET, o capital social foi analisado em suas dimensões estrutural, relacional, cognitiva e informacional (Nahapiet \& Goshal, 1998, Koka \& Prescott, 2002), de acordo as diretrizes apresentadas na Tabela 1.

\begin{tabular}{|c|c|c|c|c|}
\hline Dimensão & Estrutural & Relacional & Cognitiva & Informacional \\
\hline Conceito & $\begin{array}{c}\text { Padrão de conexão } \\
\text { entre os atores e } \\
\text { inclui conexões e } \\
\text { configurações da } \\
\text { rede }\end{array}$ & $\begin{array}{l}\text { Ativos que são } \\
\text { criados e } \\
\text { alavancados por } \\
\text { meio do } \\
\text { relacionamento }\end{array}$ & $\begin{array}{l}\text { Recursos que } \\
\text { representam visões } \\
\text { compartilhadas }\end{array}$ & $\begin{array}{c}\text { Volume, diversidade } \\
\text { e riqueza das } \\
\text { informações }\end{array}$ \\
\hline Indicadores & $\begin{array}{l}\text { Densidade, } \\
\text { Centralidade }\end{array}$ & $\begin{array}{c}\text { Identificação, } \\
\text { confiança, normas, } \\
\text { obrigações, sanções, } \\
\text { expectativas }\end{array}$ & $\begin{array}{c}\text { Linguagem, códigos } \\
\text { e narrativas }\end{array}$ & $\begin{array}{c}\text { Quantidade e } \\
\text { qualidade dos canais } \\
\text { de comunicação; } \\
\text { emissor e receptor. }\end{array}$ \\
\hline
\end{tabular}

Tabela 1: Análise das dimensões do capital social

Fonte: Elaboração própria, com base em Nahapiet e Goshal (1998) e Koka e Prescott (2002).

\section{Apresentação e Análise dos Dados}

Em 1991, foi assinado o Tratado de Assunção entre Argentina, Brasil, Paraguai e Uruguai, que deu origem ao Mercado Comum do Sul (Mercosul). Com pressuposto de integração e desenvolvimento regional, 
oito reitores de universidades públicas do Mercosul iniciaram um processo político-acadêmico até então inédito na vida universitária da região: a criação da Associação de Universidades Grupo Montevidéu (AUGM), seguindo o espírito de integração regional anunciado pelo Mercosul. Mesmo diante do moroso e ainda não resolvido mercado comum, ao contrário, o projeto AUGM vingou e ganhou autonomia a despeito do fraco sucesso de integração econômica.

Na fundação da AUGM, reuniram-se em Montevidéu (Uruguai), Reitores de oito universidades de quatro países distintos, sendo que a grande maioria (cinco) da Argentina e os outros do Brasil, Paraguai e do próprio Uruguai. Observa-se assim o primeiro impacto do capital social interpessoal, visto que cada Reitor se fez presente neste encontro por convite de algum outro Reitor conhecido. O mapa da rede em 1991 pode ser visualizado na Figura 1.

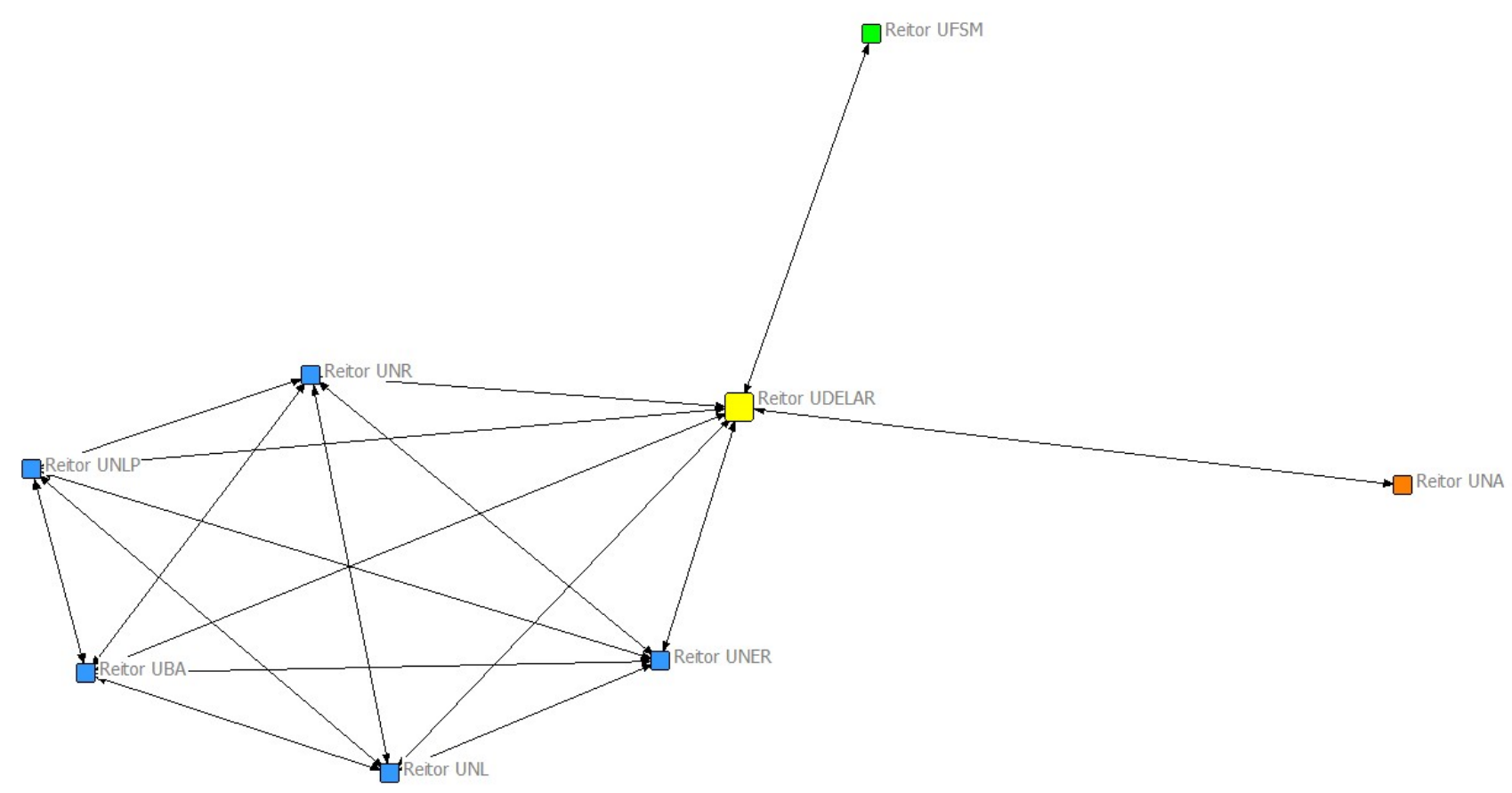

Figura 1: Mapa da rede AUGM em 1991

Fonte: Elaborado a partir dos dados da pesquisa

Segundo um dos Reitores fundadores, o motivo da reunião ter ocorrido em Montevidéu (Uruguai) foi "porque basta o Reitor da Universidad de la República (UDELAR) atravessar a rua que está no Palácio do Governo ou na sede da UNESCO". Neste ponto, compreende-se o papel de estrela exercido pelo Reitor da UDELAR na rede. Ele é o ator que controla o fluxo de comunicação por ser a ligação entre uma parte e outra da rede. Percebe-se, nesta fase inicial, que a dimensão estrutural do capital social da AUGM depende da articulação de um dos atores, que é central.

Ainda sobre estrutura, a densidade é de $60,07 \%$, significando o número de laços em relação ao total de conexões possíveis e a rede está $62,96 \%$ centralizada, devido ao peso do Reitor da UDELAR.

Quanto à dimensão relacional do capital social, como a freqüência dos encontros não estava estabelecida no momento da formação, e não foi regular nos anos iniciais, a rede era instável, com comunicações bidirecionais, com fluxo informacional pouco ágil, por não haver conexão entre todos os membros da rede, o que reitera a importância da sede como ator central.

Para conferir personalidade ao grupo fundador, fez-se a ata de fundação, caracterizando a primeira norma e o primeiro passo do capital social interpessoal na direção do capital social organizacional, sem, contudo, representar que uma organização já estava existindo. Essa foi a nota mais significativa desta dimensão no período próximo a 1991.

Quanto à dimensão que envolve a cognição, destacou-se que o desejo compartilhado de integração e fortalecimento da educação na América do Sul, foi o que permitiu a superação da barreira linguística do português para o espanhol, e mais, e mais relevante, o caráter público do ensino, valor presente na fundação e que não se alterou ao longo e nos momentos considerados para a análise, num total de vinte 
anos. Mesmo diante das trocas de presidência, do crescimento de número de membros e das vantagens que universidades privadas podem trazer, para bem ou para mal, a AUGM não alterou sua posição de ser instrumento para fortalecer exclusivamente o ensino público.

A dimensão informacional do capital social na fundação da AUGM é muito limitada pela distância geográfica, conjugada com a falta de disponibilidade de tecnologias de informação como a internet, fazendo com que as comunicações ocorressem por meio de carta ou telefone, demandando tempo e dificuldade para agendamento, implicando em pouco volume, diversidade e riqueza.

Entre 1991 a 2001, a formalização da AUGM foi intensa, com a criação de uma sede executiva para o controle de novas atividades e programas, como: o encontro dos comitês acadêmicos e núcleos disciplinares para trabalho em conjunto entre professores e alunos das universidades membro; e o programa ESCALA de mobilidade acadêmica que começou em 2000.

Com estes projetos em andamento, o estatuto da organização sofreu mudanças: o Secretário Executivo já não necessita ser o Reitor de uma das universidades membro, permanecendo no cargo o exReitor da UDELAR. Por outro lado, os novos membros deveriam ser convidados após decisão em reunião do Conselho de Reitores. Desta forma, amenizou-se as influências pessoais dos fundadores, que já não estavam mais no cargo de Reitor, e na sua maioria nem presentes nas universidades-membros.

Dessa forma, sabendo-se que para qualquer caso o capital social interpessoal sempre estará presente, nota-se na história da AUGM, enquanto organização em rede, que seu propósito é ser catalizadora de relações e incrementadora do conhecimento para os membros, na medida em que proporciona laços fracos e permite novos laços fortes; ganhando seu status organizacional por sobreviver à transição da base de sustentação, localizada na vontade pessoal dos fundadores, institucionalizando-se.

O mapa da rede em 2001 pode ser observado na Figura 2.

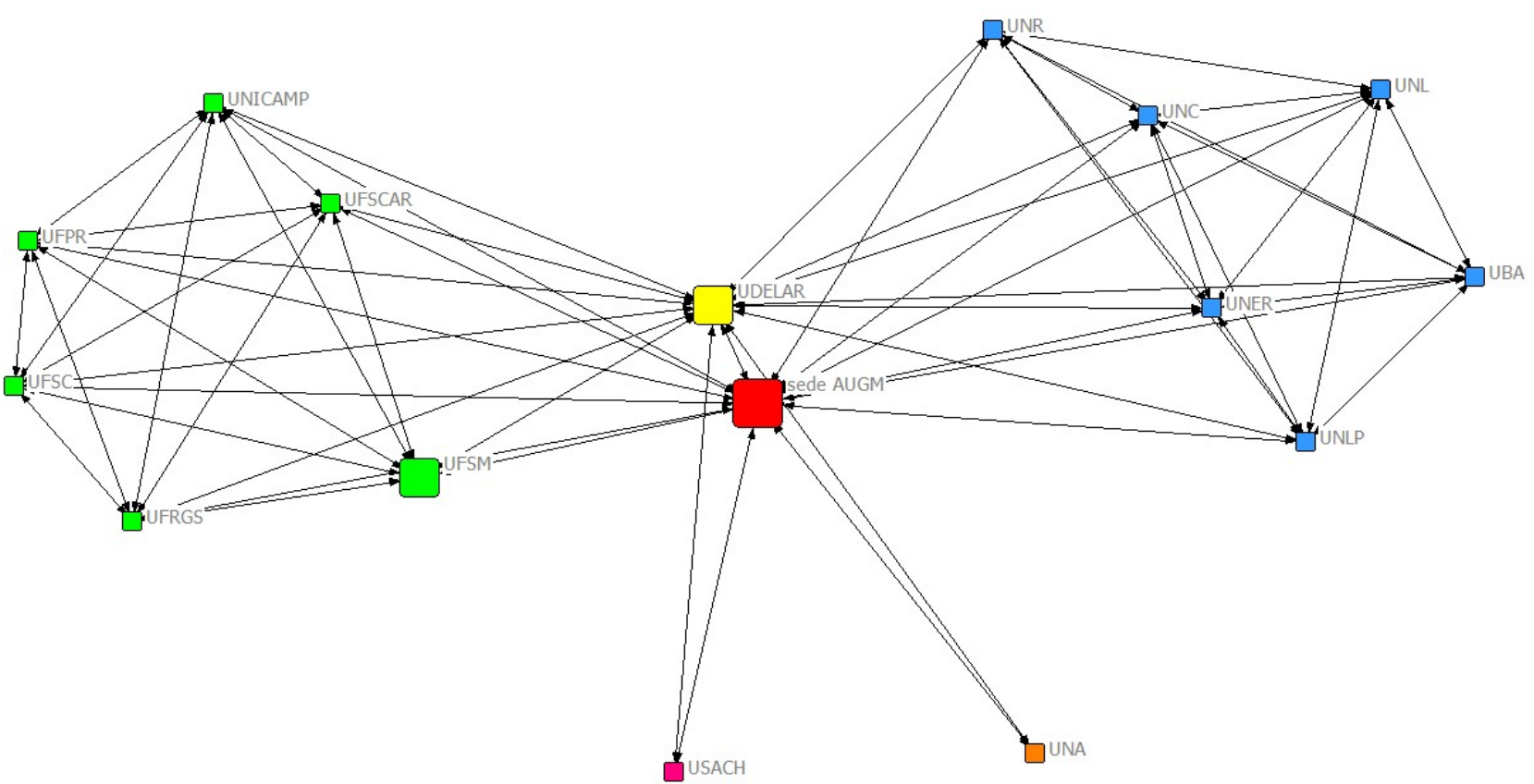

Figura 2: Mapa da rede AUGM em 2001

Fonte: Elaborado a partir dos dados da pesquisa

Na dimensão estrutural do capital social, observa-se que com o aumento do número de membros, houve dispersão dos laços na rede, com densidade é de 49,17\%, com redução da centralidade, 54,01\%, devido a presença da Sede da AUGM.

A centralidade e o papel dos atores sofre mudança, ao lado do Reitoria da UDELAR, a sede da AUGM também obtém destaque. Estes dois têm a maior capacidade de acessar, direta ou indiretamente, os outros atores da rede. Notam-se dois nós isolados, que são os casos da UNA e USACH, estas são as únicas universidades membros de seus países, Paraguai e Chile, o que explica sua posição periférica, mas não diminui sua importância como membro e como parte da proposta de integração que marca a AUGM. 
Em entrevista na Secretaria Executiva da AUGM, revela-se outra faceta da rede, a equiparação do número de universidades membro da Argentina e do Brasil. O número de membros dos dois países deve ser igual para que, sendo ambos grandes e de maior influência na América do Sul, haja equilíbrio de poder de voto na organização. Neste ponto, além da dimensão estrutural do capital social, deve-se considerar a dimensão relacional, que envolve o poder, cuja relevância, não sequer abordada na fundação em 1991.

Há um aumento na frequência e estabilidade dos laços em função da programação de atividades; algumas organizações foram formalizando sua participação na AUGM, como o caso a UFSM ao realizar a I Jornada de Jovens Pesquisadores, em 1993.

A transição do capital social interpessoal para o organizacional é notada também nas fontes secundárias, como o discurso do Reitor da UFSM (1994 a 1997) no livro comemorativo de quinze anos da AUGM:

[ ...] a primeira impressão foi de um clube de amigos. Tal a harmonia e companheirismo que encontrei entre os Reitores das Universidades que compunham a AUGM quando a eles me juntei em 1994, como Reitor recém empossado da UFSM. A convivência me mostrou que além da amizade havia intenção proposta e institucionalizada no grupo. Os valores da excelência científica, da integração latino-americana e a consciência da educação como bem maior da cidadania, sempre pontificariam nas ações da AUGM. O papel desempenhado pela AUGM no fortalecimento dos laços de integração entre as nações do Cone Sul tem sido marcante ao longo da última década. Como toda a boa causa, o êxito da AUGM se deve sem dúvida ao engajamento da comunidade acadêmica das instituições parceiras (AUGM, 2006, p. 89, grifos nossos).

As dimensões cognitiva e informacional, com a acessibilidade permitida pelos computadores e novas tecnologias de comunicação, resultaram em aprimoramento nos canais de comunicação, o que aumentou a diversidade, riqueza e volume de informações trocadas entre os membros. Além disso, é digno de nota que os recursos do computador e de tecnologia foram fatores estruturantes da AUGM e também impactaram na formação de laços, principalmente os fracos, entre os membros, sem necessitar a intermediação da Associação.

Entre 2009 e 2010 ocorreram mudanças no estatuto e na estrutura da organização: o cargo de Presidente de AUGM é assumido pelo Reitor de uma universidade membro durante um ano e tem a função de representatividade da organização, foram convidadas mais dez universidades para se tornarem membros, perfazendo um total de 29, no final desta pesquisa, conforme ilustra a Figura 3.

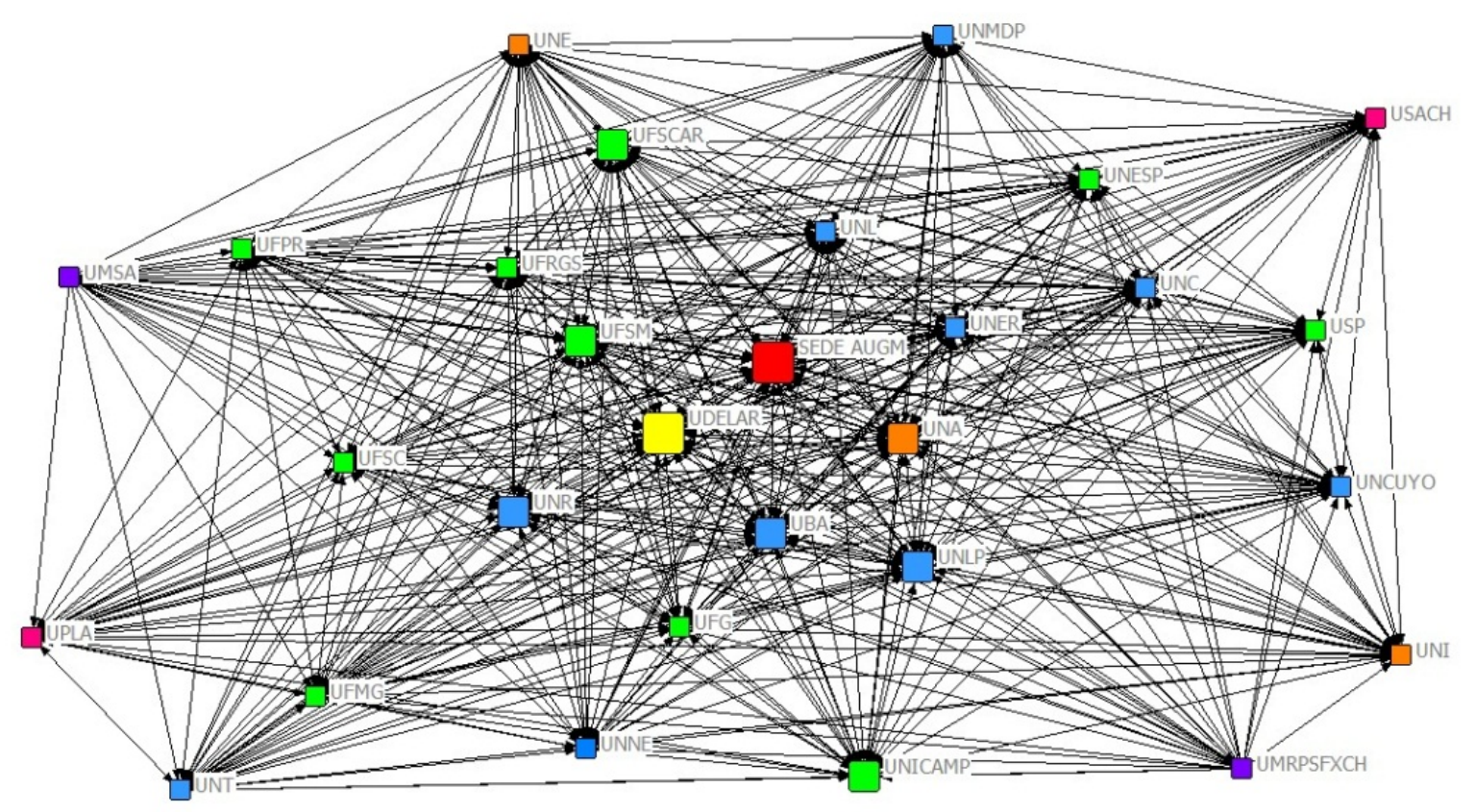

Figura 3: Mapa da rede AUGM em 2011

Fonte: Elaborado a partir de dados da pesquisa.

Quanto à dimensão estrutural do capital social, após vinte anos, a rede tornou-se mais densa $(92,26 \%)$ e com menor centralidade $(29,28 \%)$, devido a membros que se assumiram papéis relevantes na 
condução das propostas da Associação, indicando sub-redes, diminuindo o papel de porteiro como ocorria antes com a UDELAR e a sede da AUGM, com destaque regional para UNA, UNR, UFSM e UFSC. O crescimento é limitado, tornando-se muito seletiva, com recusas a novos membros.

O que se infere, do conjunto de fontes, é que a sede da AUGM exerce mais um papel de mediadora de conflitos e representante da rede, reduzindo sua ação como catalizadora, marcante em 1991 e 2001 , também se coloca menos na posição de gestora única dos programas e atividades, posicionando-se como co-gestora. Dentro desses limites, que a figura 3 foi mantida, como ilustração aceitável da condição em 2011, sendo oportuna a referência ao depoimento da coordenadora de Programas e Projetos da AUGM, que comenta sobre o funcionamento da Secretaria Executiva da sede:

[...] a AUGM tem uma Secretaria Executiva, que tem uma área técnica, que faz os programas serem desenvolvidos e se apoia em comissões que trabalham os temas. Assim, a AUGM planeja toda a arquitetura do programa e dá segmento para o programa ser operacionalizado pelas e nas universidades. São as universidades que convocam e recebem estudantes e docentes. Em geral, quando surge uma ideia para gerar um programa (como o Programa de Mobilidade para estudantes de pós-graduação), se forma uma comissão composta por um delegado de cada universidade. Essa é uma clássica forma de funcionamento da AUGM, que é através de comissões, grupos de trabalho, que são pessoas representantes de universidades que se reúnem para trocar ideias e sugestões para construir algo como uma política, um programa e para avaliar.

Em outros termos, ao se tornar mais densa, a dimensão estrutural da AUGM apresentou o fluxo de informações crescente entre os atores como a forma de uma curva de incrementos marginais decrescentes, Apesar da existência de uma sede para a Associação, os membros se comunicam entre si, diminuindo a centralização estrutural do capital social, gerando uma diferenciação entre a capacidade da rede, em termos de trocas e diversidade de trocas, e a sua gestão; em outras palavras, se destacam, ainda que coexistam, a rede de organizações, e a própria organização em rede, a AUGM.

Distinção que não pode ser ignorada, uma vez que a organização em rede, que é o caso da Associação, e que em 2011 operava conforme a última citação feita (Secretaria Executiva) é o fenômeno organizacional deste artigo, e sobre o qual é aceitável a afirmativa de que se compôs a partir do capital social interpessoal, permaneceu diante da passagem dos atores individuais, e institucionalizando-se com procedimentos e função próprias, configurando o capital social organizacional. Igualmente relevante, foi observar com base nos três momentos considerados, a evolução e mudança no papel (catalizadora para mediadora, centralizadora para co-autora).

Ainda, a conectividade não é somente suposta logicamente, ou exclusivamente baseada em testemunho, mas evidenciada nas atividades existentes na AUGM que obrigam o relacionamento entre os membros da rede, como é o caso do Programa ESCALA de Mobilidade, segundo o qual as universidades membros abrem vagas em seus cursos de interesse para intercâmbio, oferecem aos demais participantes e recebem alunos do mesmo curso de outras universidades: "Eu vim estudar na UFPR porque eu me candidatei na coordenação do meu curso lá na USACH. Eles receberam um aluno da UFPR no meu lugar" (aluno intercambista; grifo nosso para evidenciar a perda do caráter pessoal percebida na análise de 2011 ).

Em relação à dimensão relacional, os entrevistados parecem concordar que tanto a confiança quanto as normas aumentaram com o passar do tempo, sem indicação de que a confiança venha a reduzir o a normatização, ambas foram relevantes tratando-se de membros como universidades públicas (ser público é explicativo da necessidade normas detalhadas). Mesmo assim pode-se afirmar que a confiança importa mais que a norma, porque a entrada na rede depende de convite pelas universidades-membro e, secundariamente, pelo cumprimento dos requisitos. Isto é confirmado pelo depoimento de um dos funcionários da AUGM sobre a entrada da Universidade Federal de Goiás (UFG) na AUGM:

Na minha opinião, creio que com isso perdemos o que é melhor para a AUGM. Por exemplo, a Universidade de Goiás entrou para a AUGM concorrendo com a UFRJ. Para a AUGM, seria prioritário que a UFRJ fosse membro, mas entrou a de Goiás por eleição dos reitores brasileiros membros da AUGM, que respondem a outras situações e conjunturas [...] como nesse momento o Reitor de Goiás era presidente da ANDIFES, respondeu a outra necessidade, mas não era a necessidade da AUGM.

Relembrando a integração de novos membros, a coordenadora de Programas e Projetos da AUGM, comenta que no ano de 2008 uma universidade boliviana não terminou o processo de integração: “se afiliou, mas não participou". Em dezembro de 2010, ingressaram duas universidades bolivianas novas e que estão participando, reiterando uma impressão tida durante a pesquisa, de que a rede estava se estabilizando com relação ao número de membros, os 28 atuais, comportando variação de intensidade, participam efetivamente em ações da AUGM todos os anos. 
Dois atores que em 2001 são periféricos no mapa da Figura 2, continuam presentes em 2011: membros da Bolívia e do Paraguai. Em termos matemáticos seria de pouca relevância, mas dado ao caráter interpretacionista deste artigo, a permanência de representantes desses países desde a fundação da Associação indica sucesso na sua proposta de integração, que junto com a presença do Chile, somam membros bastante estáveis, não permitindo dizer que a AUGM se restringiu ao âmbito Brasil e Argentina. A ideia de integração tem seu escopo aumentado, conforme se infere no trecho seguinte, da entrevista da Coordenadora de Programas e Projetos da AUGM:

[...] algumas mais pequenas, outras de lugares menos urbanos ou mais longe das cidades mais importantes dos países. O nosso grande desafio nos últimos tempos tem sido integrar as universidades de Bolívia, que são universidades novas para nós, que tem uma realidade distinta em relação às da região do Rio de La Plata.

Quanto à dimensão informacional, além do que já foi constatado em 2001, com o impacto do uso de computadores e de tecnologias de informação e internet, que continuaram presentes e com uso mais intensificado, a principal novidade acrescentada foi a intranet, por meio da qual, a AUGM transmite a informação de uma universidade a outra e cada representante transmite dentro de sua universidade. Encontra-se em estudo uma metodologia de trabalho na intranet para atender aos núcleos e comitês acadêmicos, com dois objetivos: divulgar pesquisas e trabalhos, ou seja, criar uma biblioteca pública digital e online; e melhorar a conexão entre os membros e consolidar uma rede de intercambistas.

Esta dimensão informacional tem implicações cognitivas, inicialmente o problema era a barreira lingüística, o avanço dessa dimensão amenizou muito esta limitação, por exigir menos a fluência verbal nos idiomas, com acesso menos difícil pela linguagem escrita e também mais estruturada em função dos interesses dos membros e indivíduos que recorrem à AUGM. A compreensão envolve no estágio final da pesquisa o nível da própria rede, da troca de conhecimentos entre os membros, de uso compartilhado de recursos para pesquisa, do trânsito físico que contempla o ensino (intercambistas) e, já acenando para o futuro, a biblioteca digital como acervo do conhecimento.

Com vistas ao resumo dos vinte anos, segue-se:

- Capital social interpessoal é inicialmente a base de sustentação, em 2001 continua sendo relevante, e nitidamente perde importância em 2011, em favor do capital social organizacional;

- Esse movimento de transição implica o surgimento de uma organização a partir de capital social interpessoal, não se podendo afirmar que todo capital social interpessoal seja capaz de produzir uma organização;

- A estrutura é centralizada na fundação, o que diminui em 2001, e é menor em 2011, com a participação mais ativa de universidades membros, principalmente como propositoras de ações e gerenciadoras de atividades;

- O papel da AUGM de catalizadora e fomentadora de laços é forte em 1991 e 2001, mudando para mediadora e cogestora em 2011;

- O aspecto informacional é claramente explicado pela disponibilidade e uso de tecnologias de informação e internet, ausentes em 1991, presentes em 2001 e com novidades em 2011, como a intranet e acervo digital;

- A dimensão cognitiva não sofreu alterações quanto aos seus pressupostos de fundação em 1991 , a integração, o fortalecimento e o esforço para proporcionar o surgimento de novos laços entre universidades exclusivamente públicas. O que se observou foi maior detalhamento dos níveis, inicialmente uma proposta ampla, para a especificação de preocupações temáticas, como convênios, ações conjuntas, integração de pesquisas, intercâmbio, disponibilidade de acervo, que envolvem o trinômio conhecimento-pesquisa-ensino, com preocupação mais operacional; e

- Sobre a questão relacional, a reciprocidade esteve presente ao longo do período analisado, mas é possível se destacar as relações que envolvem diretamente a AUGM, e aquelas nas quais é coparticipante.

\section{Considerações Teóricas}

A origem e a tradição que persiste até hoje na teoria das organizações é baseada na ideia de burocracia, não se restringindo ao conceito de tipo ideal weberiano, mas também tomada como medida 
empírica das organizações. Assim, ainda são comuns análises que avaliam a complexidade por meio de especializações, níveis hierárquicos, tamanho e dispersão geográfica, ou a evolução delas como um ciclo de vida empreendedor, burocrático e flexível. Melhor do que citar exemplos é observar que a literatura mantém subjacente o conceito de burocracia, mesmo quando essa ideia é expressa por sinônimos indiretos, como formalização, institucionalização de regras e procedimentos, distância entre estrutura formal e informal, centralização do poder, entre outros. Eles representam, se não a totalidade do conceito, referências aos seus aspectos definidores.

A burocracia como parâmetro para análise organizacional faz com que as investigações privilegiem o momento no qual a organização já existe, dando pouca atenção às condições originárias de sua emergência. No caso da burocracia, já é aceito um propósito para o ator coletivo, e as pessoas que dela participam já estão em posições especializadas e hierarquizadas. Mesmo que a impessoalidade prevista no tipo ideal tenha se amenizado ao longo das pesquisas da burocracia empírica, sua ordem lógica ainda é burocracia depois pessoas, ou organização depois pessoas. Dessa forma, o contrato fundador da organização é de condições desiguais entre as pessoas.

De outro lado, a literatura que aborda capital social e redes sociais como equivalentes próximos, aponta dois caminhos. O primeiro é entender o outro como um objeto, simples parte da ação estratégica para auferir benefícios individuais, para atores individuais ou coletivos, no segundo, a preocupação é o interesse coletivo, como os estudos que envolvem cooperativas de microcrédito para agricultores, uso compartilhado de equipamentos de produção e transporte para pequenas empresas, e além da esfera econômica, as relações de trabalho voluntário, designado geralmente por terceiro setor, e o próprio caso abordado neste artigo, cuja matéria central é o compartilhamento coletivo do conhecimento.

Nessa segunda acepção, não do interesse individual, mas para o interesse coletivo, o capital social, e sua transição de interpessoal, que se institucionaliza, constituindo uma organização, tem em seu contrato fundador a igualdade entre as pessoas, e sua ordem lógica é pessoas depois organização.

Sem concluir, apenas abrindo o debate, nessa medida, o conceito de capital social é complementar para o entendimento de tipos de organizações, para as quais a tradição burocrática (empírica) é limitada, além de chamar a atenção para as condições de igualdade ou desigualdade dos membros organizacionais.

\section{Referências}

Asociacion de Universidades Grupo Montevideo (AUGM) (2006). 15 años de historia. Disponível em: <www.augm.edu.uy>. Acesso em: 10 Nov 2011.

Bourdieu, P. (1986). The forms of capital. In. Richardson, J.G. (ed.) Handbook of theory and research for the sociology of education (pp.241-258). New York: Greenwood Press.

Burt, R.S. (1992). Structural Holes: the social structures of competition. Harvard University Press.

Coleman, J. S. (1988). Social Capital in the Creation of Human Capital. American Journal of Sociology, 94, S95-S120.

Didriksson, A. (2006). La autonomia universitária desde su contemporaneidad. Universidades, 31 , 3- 16.

Godoi, C.K. et al. (2006). Pesquisa Qualitativa em Estudos Organizacionais. São Paulo: Saraiva.

Granoveter, M. (1973). The strength of weak ties. American Journal of Sociology, 78(6), pp.1360-1380.

Granovetter, M. (1992). Problems of explanation in economic sociology. In.: Nohria, N. ; Eccles, R. (eds). Networks and Organizations: Structure, Form and Action. Boston, Mass: Harvard Business School Press.

Koka, B.R. \& Prescott, J. (2002). Strategic alliances as social capital: A multidimensional view. Strategic Management journal, 23, 795-816.

Lin, N. (2001). Social Capital: A Theory of Social Structure and Action. Cambridge: Cambridge University Press.

Monge, P.R. \& Contractor, N.S. (2001). Emergence of communication networks. In F.M. Jablin \& L.L. Putnam (eds.), New handbook of organizational communication (pp. 440-502). Newbury Park, CA: Sage.

Nahapiet, J. \& Ghoshal, S. (1998). Social Capital, intellectual capital and the organizational advantage. Academy of Management Review, 23(2), 242-266. 
Portes, A. (1988). Social Capital: Its Origins and Applications in Modern Sociology. Annual Review of Sociology, 24.

Putnam, R. D. (2000). Bowling alone: the collapse and revival of American community. New York: Simon \& Schuster.

Sebastián, J. (2004). Cooperação e Internacionalização das Universidades. Argentina: Editorial Biblos.

Wasserman, S. \& Faust, K. (1994). Social Network Analysis: Methods and Applications. Cambridge: Cambridge University Press. 